\title{
Lenalidomide in the context of complex karyotype or interrupted treatment: case reviews of del(5q)MDS patients with unexpected responses
}

\author{
Aristoteles A. N. Giagounidis • Sabine Haase • \\ Michael Heinsch • Gudrun Göhring • \\ Brigitte Schlegelberger • Carlo Aul
}

Received: 8 July 2006 / Accepted: 18 October 2006 / Published online: 17 November 2006

(C) Springer-Verlag 2006

\begin{abstract}
Lenalidomide has particular activity in patients with transfusion-dependent del(5q) myelodysplastic syndromes (MDS), but mechanistic information is limited regarding the relationship between erythroid and cytogenetic responses. We reviewed medical records from three distinct subgroups of $\operatorname{del}(5 \mathrm{q})$ MDS patients who had unexpected effects with lenalidomide treatment: 1. two patients with complex karyotypes who achieved both cytogenetic remissions and transfusion independence; 2. two patients with $5 \mathrm{q}$ - syndrome who took lenalidomide for less than 12 weeks but remained transfusion independent for $15+$ months still displaying $\operatorname{del}(5 \mathrm{q})$ metaphases after 6 and 12 months; and 3. one patient who was a nonresponder on lenalidomide during treatment but became transfusion independent for $13+$ months after discontinuation. All but the latter patient in this series had reduction of affected metaphases, suggesting that erythroid responses might be mediated by result from partial or complete suppression of the malignant clone, either directly or indirectly through modulation of the bone marrow microenvironment. These clinical observations illustrate the heterogeneity of del(5q)MDS pathogenesis and the diversity of lenalidomide responses within this patient subset.
\end{abstract}

\footnotetext{
A. A. N. Giagounidis $(\square) \cdot$ S. Haase $\cdot$ M. Heinsch $\cdot$ C. Aul Medizinsche Klinik II, St. Johannes Hospital,

An der Abtei 7-11,

47166 Duisburg, Germany

e-mail: gia@krebs-duisburg.de

G. Göhring • B. Schlegelberger

Institut für Zell- und Molekularpathologie,

Medizinische Hochschule Hannover,

Carl-Neuberg-Str.1,

30625 Hannover, Germany
}

Keywords Lenalidomide - Myelodysplastic syndromes . $\operatorname{del}(5 q)$ MDS $\cdot$ Transfusion-dependent · Case studies

\section{Introduction}

Myelodysplastic syndromes (MDS) with chromosomal deletion of $5 \mathrm{q}[\operatorname{del}(5 \mathrm{q}) \mathrm{MDS}]$ are heterogeneous diseases $[3,5]$. Apart from the $5 q$ - syndrome $[7,16]$, patients with del(5q) MDS may present with one additional chromosomal abnormality, with multiple additional chromosomal abnormalities leading to a complex karyotype, or with an increase of bone marrow and/or peripheral blasts irrespective of chromosomal complexity. These distinct disease subgroups have dramatically different prognostic features $[3,5,6,12]$.

Lenalidomide is a thalidomide analog with a distinct clinical profile that has demonstrated erythroid responses leading to RBC transfusion independence, particularly in $\operatorname{del}(5 \mathrm{q})$ MDS $[10,11]$ and in some patients with Low or Int-1 MDS lacking the del(5q) chromosomal abnormality [14]. Although the exact mechanism of action has not been defined, lenalidomide is known to have multiple biological activities including anti-angiogenesis, immunomodulation, anti-cytokine, and direct toxic effects on malignant bone marrow cells $[1,4]$.

We experienced unexpected effects of lenalidomide in del(5q) MDS patients that are suggestive of the mode of action in this patient subgroup and may have implications for future use of the substance in this patient population. To our knowledge, these types of responses to lenalidomide have not been previously described. 


\section{Study design}

Between November 2003 and May 2006, 43 patients with $\operatorname{del}(5 q)$ MDS with or without additional chromosomal abnormalities were treated with lenalidomide at St. Johannes Hospital, Medizinsche Klinik II, Duisburg, Germany. As of December 27, 2005, lenalidomide has been approved for clinical use in the United States, but not in Europe. These patients received lenalidomide as participants of clinical trials or through an expanded access program. Of the cases reported in this paper, only one patient took part in a lenalidomide clinical trial, and that patient was a non-responder. Patients were informed of inclusion of their information in the present report and consent was given.

\section{Results and discussion}

Patients with complex karyotypes

\section{Patient 1}

A 59-year-old man diagnosed in October 2005 with International Prognostic Scoring System (IPSS) [9] Int-2 risk MDS, $>5 \%$ bone marrow blasts (RAEB-I) [2, 17], one cytopenia, and complex karyotype: 44, XY, del (5) (q13q33), -7, -15, -18, -19, -19, + $\operatorname{mar}(15) / 46, X Y(7)$ was transfusion-dependent and received two units of packed RBC every 2 to 3 weeks since diagnosis. He had a previous history of two myocardial infarctions, insulin-dependent diabetes mellitus, arterial hypertension, and deep venous thrombosis. Treatment with lenalidomide (10 $\mathrm{mg}$ p.o., once daily) commenced in December 2005 and this patient has remained on treatment as of May 2006. He experienced grade 1 neutropenia and grade 2 thrombocytopenia, which required no treatment. The time to transfusion independence was immediate; no further transfusions were required after the initiation of lenalidomide treatment. Hemoglobin was $>13 \mathrm{~g} / \mathrm{dl}$ after 8 weeks, although the time to normalization of hemoglobin (normal level at local laboratory $=14 \mathrm{~g} / \mathrm{dl}$ ) has not been reached. Repeat cytogenetic analyses conducted in January and March 2006 showed consistent reductions in the number of abnormal metaphases (Table 1).

\section{Patient 2}

A 78-year-old woman with IPSS Int-1 MDS [no blasts, one cytopenia, complex karyotype: $46, \mathrm{XX}, \operatorname{der}(1) \mathrm{t}(1: 2)(\mathrm{p} 13 ; ?)$, $\operatorname{der}(2) \mathrm{t}(1 ; 2)(\mathrm{p} 13 ; \mathrm{q} 31) \operatorname{del}(2)(\mathrm{p} 23), \operatorname{del}(5)(\mathrm{q} 15 \mathrm{q} 31)(19) / 46$, XX (1)], who was diagnosed in March 2004, had an RBC transfusion requirement of two packed RBC every 8 weeks. This lady's case report has been published in an earlier
Table 1 Sequential bone marrow cytogenetic analyses

\begin{tabular}{|c|c|c|}
\hline $\begin{array}{l}\text { Patient } \\
\text { number }\end{array}$ & $\begin{array}{l}\text { Analysis } \\
\text { date }\end{array}$ & Karyotype \\
\hline \multirow[t]{3}{*}{1} & $10 / 2005$ & $\begin{array}{l}\text { 44, XY, del(5)(q13q33), }-7,-15,-18,-19, \\
-19,+3 \operatorname{mar}[15] / 46, X Y[7]\end{array}$ \\
\hline & $1 / 2006$ & $\begin{array}{l}\text { 44, XY, del(5)(q13q33), }-7,-15, \operatorname{add}(18) \\
(\mathrm{p} 11),-19, \operatorname{add}(19)(\mathrm{q} 12)[8] / 46, \mathrm{XY}[7]\end{array}$ \\
\hline & $3 / 2006$ & $\begin{array}{l}45, \mathrm{XY}, \operatorname{del}(5)(\mathrm{q} 13 \mathrm{q} 33),-7, \operatorname{der}(12 ; 14) \\
(\mathrm{q} 10 ; 10),-14,-15, \operatorname{add}(18)(\mathrm{p} 11),-19, \\
\operatorname{add}(19)(\mathrm{q} 12),+3 \operatorname{mar}[3] / 46 ; \mathrm{XY}[17]\end{array}$ \\
\hline \multirow[t]{4}{*}{2} & $3 / 2004$ & $\begin{array}{l}\text { 46, XX, der(1)t(1;2)(p13;?), der(2)t(1;2) } \\
(\mathrm{p} 13 ; \mathrm{q} 31) \operatorname{del}(2)(\mathrm{p} 23), \operatorname{del}(5)(\mathrm{q} 15 \mathrm{q} 31) \\
{[19] / 46, X X[1]}\end{array}$ \\
\hline & $\begin{array}{r}12 / 2004 \\
(\mathrm{FISH})\end{array}$ & No evidence of $5 \mathrm{q} 31$ deletion \\
\hline & $\begin{array}{l}\text { 6/2005 } \\
\text { (FISH) }\end{array}$ & No evidence of $5 \mathrm{q} 31$ deletion \\
\hline & $1 / 2006$ & No evidence of $5 \mathrm{q} 31$ deletion \\
\hline \multirow[t]{2}{*}{3} & $2 / 2004$ & $46, X X, \operatorname{del}(5)(q 13 q 33)[20]$ \\
\hline & $5 / 2005$ & $46, X X, \operatorname{del}(5)(q 13 q 33)[12] / 46, X X[13]$ \\
\hline \multirow[t]{2}{*}{4} & $5 / 2004$ & $46, \mathrm{XY}, \operatorname{del}(5)(\mathrm{q} 13 \mathrm{q} 33)[20]$ \\
\hline & $12 / 2005$ & 46, XY, del(5)(q13q33) [13]/ 46, XY [8] \\
\hline \multirow[t]{7}{*}{5} & $1 / 1996$ & $46, X X, \operatorname{del}(5)(q 13 q 33)[15]$ \\
\hline & $10 / 2002$ & No change, non-mosaic pattern of del(5q) \\
\hline & $3 / 2003$ & \\
\hline & $12 / 2003$ & \\
\hline & $6 / 2004$ & \\
\hline & $11 / 2004$ & \\
\hline & $06 / 2006$ & \\
\hline
\end{tabular}

(FISH) indicates that additional fluorescence in situ hybridization was performed.

issue of this journal, but with a shorter follow-up [6]. She had a previous medical history of grade 1 renal insufficiency. Treatment with lenalidomide (10 mg p.o. once daily) commenced in July 2004. The dosage was reduced to $5 \mathrm{mg}$ p.o. once daily from November 2004 to November 2005, and was subsequently reduced to $5 \mathrm{mg}$ p.o. every other day from November 2005 to present. The actual treatment duration was 22 months.

Adverse events included grade 2 neutropenia, grade 2 thrombocytopenia, and grade 3 scalp itching. Whereas neutropenia and thrombocytopenia required no additional medication, scalp itching was treated with antihistamines and low doses of prednisone $(10 \mathrm{mg})$ for 2 weeks. Transfusion independence was reached after 1 month and normalization of hemoglobin was reached after 4 months of treatment. Repeat cytogenetic analyses showed complete cytogenetic remission with no evidence of 5(q31) deletion in December 2004 (4 months after start of treatment), in June 2005 and in January 2006 (Table 1). This del(5q) patient with a complex karyotype achieved both durable complete cytogenetic remission and long-term RBC transfusion independence. 
Patients with transfusion independence despite long-term interruption of medication

\section{Patient 3}

A 33-year-old woman was diagnosed in February 2004 with IPSS Low-risk MDS (no blasts, one cytopenia) and del (5)(q13q33) as the sole karyotypic abnormality, disease characteristics that are consistent with $5 \mathrm{q}$ - syndrome. She had a transfusion requirement of two packed RBC units every 3 to 4 weeks. Lenalidomide treatment was started in November 2004, but therapy was interrupted after 28 days for erythematous lesions of the skin and grade 4 neutropenia. Transfusion independence was reached after 8 weeks without further medication and normalization of hemoglobin was achieved after 20 weeks. Grade 1 neutropenia persisted. Repeat bone marrow cytogenetics in May 2005 showed a reduction in $\operatorname{del}(5 \mathrm{q})$ metaphases (Table 1). Although treatment was interrupted due to toxicity, this patient continued to improve with respect to both erythroid response and the number of $\operatorname{del}(5 q)$ metaphases. This patient remains transfusion independent at 21 months after commencement of lenalidomide therapy and 20 months after discontinuation of therapy.

\section{Patient 4}

A 49-year-old man with IPSS Low-risk MDS typical of 5qsyndrome [no blasts, one cytopenia, isolated del(5) (q13q33)] was diagnosed May 2004. He was transfusiondependent, requiring two packed RBC units every 2 weeks before the start of lenalidomide therapy in November 2004. However, treatment was stopped after 12 weeks (February 2005) because of grade 3 skin itching. Transfusion independence had been reached after 8 weeks of treatment. Normalization of hemoglobin was achieved after 16 weeks and was ongoing at last visit (21 months) despite receiving no additional treatment. Mild leukopenia has persisted. A repeat karyotype analysis in December 2005 (13 months after onset of therapy) showed a reduction in $\operatorname{del}(5 \mathrm{q})$ metaphases and no evidence of cytogenetic evolution (Table 1). The lengthy duration of response in this patient was notable and unexpected considering the relatively short treatment period and the persistence of the $\operatorname{del}(5 \mathrm{q})$ clone.

Patient with no response during treatment but transfusion independence after discontinuation

\section{Patient 5}

A 58-year-old woman with no relevant previous history was diagnosed January 1996 with IPSS Low-risk MDS (no blasts, one cytopenia) with $\operatorname{del}(5)(q 13 q 33)$ as the sole karyotypic abnormality. She was transfusion-dependent, receiving two packed RBC units every 4 weeks. Low-dose cytarabine was given in December 1996, resulting in 10 months of transfusion independence, but was again given in January 1998 without effect. All-trans-retinoic acid was administered from July 2002 to January 2003 without improvement of transfusion burden. She subsequently received lenalidomide from January 2004 to November 2004 without reduction in transfusions.

This prolonged treatment of more than 10 months was administered in the hope of induction of a late response to the drug. Her hemoglobin value at commencement of lenalidomide therapy was $7.1 \mathrm{~g} / \mathrm{dl}$, and she needed two red blood cell transfusions every 3 weeks to maintain these levels throughout drug intake. However, 16 weeks after lenalidomide discontinuation, transfusion independence was achieved in this patient (March 2005) and without additional measures. The response had been ongoing for 16 months, without normalization of hemoglobin $(10.9 \mathrm{~g} / \mathrm{dl}$ at last visit in June 2006). Six repeat karyotype analyses from Oct 2002 to June 2006 all showed the initial finding of a non-mosaic pattern of $\operatorname{del}(5 \mathrm{q})$ (Table 1$)$.

\section{Discussion}

Clinical trials of lenalidomide have demonstrated cytogenetic and erythroid responses in patients with del(5q) MDS $[10,11]$ that have not been achieved with other noncytotoxic agents [8]. The activity of lenalidomide in patients with complex karyotypes including del $(5 q)$ represents a major advance, as those patients have an ominous prognosis and are expected to transform rapidly to acute myeloid leukemia [6]. Patient 1, who had Int-2 MDS with $\operatorname{del}(5 q)$ and a complex karyotype, is of special interest because repetitive karyotyping showed the number of affected metaphases to be gradually reduced during lenalidomide treatment. Patient 2, who also had $\operatorname{del}(5 \mathrm{q})$ with a complex karyotype, experienced both complete cytogenetic response and normalization of hemoglobin. Two other patients with complex cytogenetic abnormalities are being treated at our institution, but the duration of treatment is too short for final evaluation.

Whereas cytogenetic remission with lenalidomide treatment correlates closely with erythroid response [10], complete suppression of the malignant clone was not required for transfusion independence in four of the five cases (patients 1, 3, 4, and 5) reported here. Hematologic remissions occurred in three patients despite treatment interruption and persistence of the $\operatorname{del}(5 \mathrm{q})$ karyotype (patients 3, 4, and 5). Patient 5 had a late effect and reached transfusion independence after discontinuation of lenalidomide. The long-term hematologic responses seen 
with patient $3 / 4$ patients may be an exception, as another patient at our department had worsening of anemia 3 months after stopping lenalidomide after a short period of administration (5 weeks).

Two other patients at our institution had interrupted lenalidomide treatment after prolonged intake (at months 24 and 13 , respectively) in complete hematologic and cytogenetic remission for reasons other than an adverse event. Both patients remain in complete hematologic remission, ongoing for more than 6 and 21 months. Thus, altogether six out of 43 patients at our site have interrupted lenalidomide treatment for non-toxicity reasons. Five experienced an ongoing erythroid response and one patient relapsed after 3 months.

Although all of the patients reported here have achieved transfusion independence, lenalidomide treatment does not uniformly lead to transfusion independence in $\operatorname{del}(5 \mathrm{q})$ MDS. Of note, the lenalidomide MDS 003 study in del (5q) MDS patients shows that recurrence of the cytogenetic aberration or cytogenetic evolution is not an uncommon feature in this patient population during lenalidomide treatment: New chromosomal abnormalities occurred in 24 out of 119 patients, and no single type was seen in more than one patient [10]. Interestingly, chromosome 7 abnormalities occurred in only one patient, in contrast with the higher incidence in the MDS 001 study [11].

List et al. suggested that lenalidomide may act by suppression of the del(5q) clone [11]. All but one patient in our series reported here had reduction of affected metaphases, which supports this hypothesis. However, this may not be a result of an immediate cytotoxic effect, as evidenced by the slow decrease in malignant metaphases as seen with patient 1 . The other responding patients, particularly patient 5 , showed a slow erythroid response more consistent with a sustained effect on the bone marrow microenvironment. Effective bone marrow modulation might, in some instances, lead to (partial) suppression of $\operatorname{del}(5 q)$ clones. However, even if clonal suppression did not occur, normal hematopoiesis may be sufficiently strengthened to support a partial erythroid response in some patients.

Examples of such erythroid response without alteration of the underlying cytogenetic abnormality have occurred in studies with other immunomodulating drugs like antithymocyte globulin and cyclosporine A [15], differentiationinducing agents like all-trans-retinoic acid [8], and with cytokine treatment like darbepoietin [13]. Thus, among individual patients within the del(5q) MDS subset, lenalidomide may affect the del(5q) clone and the bone marrow microenvironment to different degrees to result in hematopoietic normalization. Further study is needed to better understand the relationship between erythroid response and cytogenetic remission with lenalidomide treatment.
In conclusion, although the above case reports obviously represent only selected cases out of a larger number of lenalidomide treated $\operatorname{del}(5 \mathrm{q})$ MDS patients, these unusual and unexpected cytogenetic and erythroid responses suggest that some patients with complex karyotypes including del(5q) or who discontinue therapy may still benefit from lenalidomide treatment.

Acknowledgement We thank Celgene Corporation for providing lenalidomide for this case series. This work was supported by a grant from the German Bundesministerium für Bildung und Forschung (BMBF), Kompetenznetz "akute und chronische Leukämien."

\section{References}

1. Bartlett JB, Dredge K, Dalgleish AG (2004) The evolution of thalidomide and its IMiD derivatives as anticancer agents. Nat Rev Cancer 4:314-322

2. Bennett JM, Catovsky D, Daniel MT, Flandrin G, Galton DA, Gralnick HR, Sultan C (1982) Proposals for the classification of the myelodysplastic syndromes. Br J Haematol 51:189-199

3. Dewald GW, Davis MP, Pierre RV, O'Fallon JR, Hoagland HC (1985) Clinical characteristics and prognosis of 50 patients with a myeloproliferative syndrome and deletion of part of the long arm of chromosome 5. Blood 66:189-197

4. Dredge K, Horsfall R, Robinson SP, Zhang LH, Lu L, Tang Y, Shirley MA, Muller G, Schafer P, Stirling D, Dalgleish AG, Bartlett JB (2005) Orally administered lenalidomide (CC-5013) is anti-angiogenic in vivo and inhibits endothelial cell migration and Akt phosphorylation in vitro. Microvasc Res 69:56-63

5. Giagounidis AA, Germing U, Haase S, Hildebrandt B, Schlegelberger B, Schoch C, Wilkens L, Heinsch M, Willems H, Aivado M, Aul C (2004) Clinical, morphological, cytogenetic, and prognostic features of patients with myelodysplastic syndromes and del $(5 q)$ including band $\mathrm{q} 31$. Leukemia 18:113-119

6. Giagounidis AA, Germing U, Strupp C, Hildebrandt B, Heinsch M, Aul C (2005) Prognosis of patients with del(5q) MDS and complex karyotype and the possible role of lenalidomide in this patient subgroup. Ann Hematol 84:569-571

7. Giagounidis AA, Germing U, Wainscoat JS, Boultwood J, Aul C (2004) The 5q- syndrome. Hematology 9:271-277

8. Giagounidis AA, Haase S, Germing U, Schlegelberger B, Wilkens L, Busche G, Kreipe HH, Wysk J, Grips KH, Grabenhorst U, Rothmann F, Lubbert M, Ganser A, Aivado M, Heinsch M, Aul C (2005) Treatment of myelodysplastic syndrome with isolated del (5q) including bands q31-q33 with a combination of all-transretinoic acid and tocopherol-alpha: a phase II study. Ann Hematol 84:389-394

9. Greenberg P, Cox C, LeBeau MM, Fenaux P, Morel P, Sanz G, Sanz M, Vallespi T, Hamblin T, Oscier D, Ohyashiki K, Toyama K, Aul C, Mufti G, Bennett J (1997) International scoring system for evaluating prognosis in myelodysplastic syndromes. Blood 89:2079-2088

10. List A, Dewald G, Bennett J, Giagounidis A, Raza A, Feldman E, Powell B, Greenberg P, Thomas D, Stone R, Reeder C, Wride K, Patin J, Schmidt M, Zeldis J, Knight R (2006) Lenalidomide in the myelodysplastic syndrome with chromosome $5 \mathrm{q}$ deletion. $\mathrm{N}$ Engl J Med 355:1456-1465

11. List A, Kurtin S, Roe DJ, Buresh A, Mahadevan D, Fuchs D, Rimsza L, Heaton R, Knight R, Zeldis JB (2005) Efficacy of lenalidomide in myelodysplastic syndromes. $N$ Engl J Med 352:549-557 
12. Malcovati L, Porta MG, Pascutto C, Invernizzi R, Boni M, Travaglino E, Passamonti F, Arcaini L, Maffioli M, Bernasconi P, Lazzarino M, Cazzola M (2005) Prognostic factors and life expectancy in myelodysplastic syndromes classified according to WHO criteria: a basis for clinical decision making. J Clin Oncol 23:7594-7603

13. Mannone L, Gardin C, Quarre MC, Bernard JF, Vassilieff D, Ades L, Park S, Vaultier S, Hamza F, Beyne-rauzy MO, Cheze S, Giraudier S, Agape P, Legros L, Voillat L, Dreyfus F, Fenaux P (2006) High-dose darbepoetin alpha in the treatment of anaemia of lower risk myelodysplastic syndrome results of a phase II study. Br J Haematol 133:513-519

14. Raza A, List A, Bennett J, Dewald G, Feldman F, Reeves J, Shadduck J, Zeldis J, Knight R (2005) Lenalidomide (CC5013)induced red blood cell (RBC) transfusion-independence (TI) responses in low-/int-1 risk patients with myelodysplastic syn- dromes (MDS): results of the multicenter MDS 002 study. Leukemia Research 29 (suppl 1):S70

15. Stadler M, Germing U, Kliche KO, Josten KM, Kuse R, Hofmann WK, Schrezenmeier H, Novotny J, Anders O, Eimermacher H, Verbeek W, Kreipe HH, Heimpel H, Aul C, Ganser A (2004) A prospective, randomised, phase II study of horse antithymocyte globulin vs rabbit antithymocyte globulin as immune-modulating therapy in patients with low-risk myelodysplastic syndromes. Leukemia 18:460-465

16. Van den Berghe H, Cassiman JJ, David G, Fryns JP, Michaux JL, Sokal G (1974) Distinct haematological disorder with deletion of long arm of no. 5 chromosome. Nature 251:437-438

17. Vardiman JW, Harris NL, Brunning RD (2002) The World Health Organization (WHO) classification of the myeloid neoplasms. Blood 100:2292-2302 